\title{
Chronic Pain Patient "Advocates" and Their Focus on Opiophilia: Barking Up the Wrong Tree?
}

\author{
Michael E Schatman (iD) ${ }^{1-3}$ \\ Hannah Shapiro ${ }^{3,4}$ \\ 'Division of Medical Ethics, NYU School \\ of Medicine, New York, NY, USA; \\ ${ }^{2}$ Department of Anesthesiology, \\ Perioperative Care, and Pain Medicine, \\ NYU School of Medicine, New York, NY, \\ USA; ${ }^{3}$ School of Social Work, North \\ Carolina State University, Raleigh, NC, \\ USA; ${ }^{4}$ McLean Hospital, Division of \\ Alcohol, Drugs, and Addiction, Harvard \\ Medical School, Boston, MA, USA
}

The "war on opioids" is well publicized, albeit sometimes misguided. Much has been written on how efforts to reduce the flow of prescription opioids have morphed into a war on chronic pain patients. ${ }^{1-3}$ There have been numerous editorials and articles published expressing concerns regarding the unfortunate consequences of the resulting "opiophobia" and "oligoanalgesia", $3-5$ and many other key opinion leaders have and continue to express similar concerns. ${ }^{6-9}$ Efforts to counteract these tragic consequences have met with a degree of success, although much more needs to be done if chronic pain patients for whom there are frequently no other viable, accessible alternatives to opioid analgesia are to regain access to judiciously prescribed opioids.

Unfortunately, advocacy for patients with pain, particularly on social media, has seemingly devolved into purely advocacy for access to opioids. We see this as problematic on a number of levels. First and foremost, opioids are not the only treatment for many types of chronic pain, and certainly not necessarily the safest and most effective. Pain management should be based on best practices guided by clinical judgement and the supporting science. ${ }^{10-12}$ Opioids and other analgesics, as well as many procedures and surgeries, generally represent purely biomedical approaches to chronic pain. Over 2 decades ago, Rollin "Mac" Gallagher astutely noted that "The history of pain medicine is replete with failures of the biomedical model". ${ }^{13}$ (p. 559). Numerous others with broader understandings of pain management have subsequently echoed his sentiments. $^{14-18}$ The importance of providing chronic pain patients with education in order to help them reconceptualize their pain away from flawed biomedical approaches has also been addressed in the literature. ${ }^{19,20}$ Accordingly, we posit that advocating solely for access to opioid analgesia is in fact advocating for ineffective, purely biomedical care, as opposed to coordinated interdisciplinary treatment that is likely to be far more beneficial for most patients.

Second, the image of patients with chronic pain (as well as that of many of us who treat them) is less than stellar at this juncture. Radically anti-opioid forces have done their best to discredit patients with chronic pain through the use of stigmatizing and marginalizing rhetoric and hyperbole. For example, when interviewed for an article published in the Richmond Times-Dispatch in 2015, Andrew Kolodny (an addiction psychiatrist, not a pain physician) reportedly stated, "When we talk about opioid painkillers we are essentially talking about heroin pills". ${ }^{21}$ More recently, Dr Keith Humphreys (an addiction psychologist, not a pain psychologist) testified to a US House of Representatives subcommittee, stating "as long as we continue putting countless Americans in 'heroin
Correspondence: Michael E Schatman Population Health, NYU School of Me 550 First Avenue, New York, NY, 10016 , USA

Tel + I 425-647-4880

Email Michael.Schatman@NYULangone.org 
prep school' each year by overprescribing opioids, the next generation of users will soon replace those who exit the heroin market". 22 In addition to both of these statements being inaccurate, anti-scientific rhetoric and hyperbole has had a negative psychological impact on patients with chronic pain, which some believe has contributed to their development of a sense of worthlessness and futility, and appears to be one of the causes of suicidality in these patients. ${ }^{23-25}$ By striving solely for increased access to opioid analgesia, these advocates have essentially reinforced the message that their anti-opioid detractors have deviously developed, ie, that all chronic pain sufferers are actually a group of medication-seeking addicts.

Third, social media has seen the ascendence of pro-opioid rhetoric, hyperbole, and disregard for science. For example, pro-opioid crusaders, including a small group of physicians, have insisted that any treatment other than opioids is of no medical value to chronic pain patients. We recently addressed the ridiculous falsehood that has been disseminated regarding spinal cord stimulation "killing thousands of patients every year" due to malfunction. ${ }^{26}$ Perhaps due to the marginalizing language of a small group of the harshest critics of opioid analgesia, a small group of so-called "patient advocates" have convinced patients who are vulnerable and often uninformed that any treatments other than opioids are ineffective and likely dangerous, and we express concern that this has resulted in too many patients becoming convinced that it is in their best interests to reject the offers of any treatments that are not opio-centric. These treatments include interdisciplinary chronic pain management, interventional approaches, complementary/integrative approaches, and even necessary surgeries. The ascendence of Enhanced Recovery after Surgery (ERAS) protocols has resulted in some anti-opioid pain management "specialists" misrepresenting the science behind and the "universal" effectiveness of enhanced recovery approaches, and we have addressed the need to consider ERAS protocols as "opioid-sparing" as opposed to "opioid eradicating". 27 Irrespective, reports of patients who have awakened from anesthesia in unbearable pain and being refused medication other than acetaminophen or NSAIDs, even if this occurs in very few cases, has led to many patients deciding to forego elective surgeries - including those commonly utilized as an effective approach to gaining long-term pain relief (eg, total knee and hip arthroplasties).

Finally, it is apparent that legitimate pain patient advocacy groups, such as the American Chronic Pain Association and the US Pain Foundation, among several others, are doing excellent work to promote access to high-quality patientcentered pain care, rather than simply clamoring for increased access to opioid analgesics. Those groups that are solely focused on access to opioids are guilty of reliance on "junk science" to "prove" that opioids are a panacea for chronic pain universally, mirroring the reliance on poor quality data by the most extreme of the anti-opioid faction to support their assertion that any exposure to opioids, even in acute settings, puts opioid-naïve patients at "great risk" for developing an opioid use disorder (OUD). For example, in a recent article on the risk of nonmedical opioid use behavior, the authors included "request for specific opioid" by a patient in their list of risk factors, even though this has never been empirically established. ${ }^{28}$ The inclusion of this and other behaviors that most clinicians consider benign served to inflate the authors' conclusion that $19 \%$ of cancer pain patients demonstrate nonmedical opioid use, which is quite inconsistent with the findings of a more methodologically sound study in which a range of $3.2 \%$ to $4.3 \%$ was determined among cancer survivors requiring opioid analgesia. ${ }^{29}$ As the authors' inflation of the prevalence of opioid misuse had the potential to result in higher levels of oligoanalgesia, broadly, a letter to the editor elucidating issues with the quality of the science was written and published. ${ }^{30}$ Groups that are solely focused on increasing access to opioid analgesia do not produce data, as they are not researchers. However, they cherry-pick data in order to "prove" that opioids are completely safe. For example, a recent systematic review and meta-analysis ${ }^{31}$ found that the prevalence of problematic opioid use among chronic noncancer pain patients ranged from $3.2 \%{ }^{32}$ to as high as $80.5 \%$, ${ }^{33}$ with the authors of the review concluding an estimated prevalence of $36.3 \%$. Although this figure may seem high, we are puzzled by the common assertion of "patient advocates" on social media that the figure is less than $1 \%$. Misrepresentation of data and intentionally flawed methodology are never appropriate, irrespective of the side of an argument which one supports.

\section{Conclusions, Recommendations}

Forced tapers from opioids in adherent and stable chronic pain patients for whom there are no realistic, accessible alternatives represent a humanitarian crisis, ${ }^{34}$ and our hope is that society is in the process of reversing this trend. Chronic pain patients whose quality of life have been adversely affected by antiopioid rhetoric and hyperbole as well as poor quality and misrepresented data have resulted in a need for sound and moderated patient advocacy. That the quality of medical advice regarding pain management on social media is woefully poor has been empirically established. ${ }^{35}$ Social media serves as a sounding board in which patients suffering from chronic pain and its sequelae can vent their frustrations and support 
each other and can be beneficial in this regard. Additionally, a number of medically trained key opinion leaders with lengthy histories of pain patient advocacy contribute to the social media chronic pain discourse, providing much-needed accurate information and even making referrals to high-quality pain care providers to patients who lack the ability to access these excellent clinicians on their own. However, we have recently observed an increase in self-proclaimed pain patient "advocates" dedicating their efforts to help their peers solely to advocating for increased access to opioid analgesia, "demanding" that patients are prescribed the same high dosages that were prescribed a decade ago, which have not been empirically established as safe or effective. In doing so, their efforts are misguided, as they exacerbate the stigmatization and marginalization that chronic pain patients already find so deleterious, as well as dissuade them from consideration of the numerous non-opioid treatments for chronic pain that have the potential to improve patients' quality of life.

\section{Disclosure}

Dr Michael E Schatman serves as a research consultant for Modoscript, outside the submitted work. The authors report no other conflicts of interest in this work.

\section{References}

1. Atkinson TJ, Schatman ME, Fudin J. The damage done by the war on opioids: the pendulum has swung too far. $J$ Pain Res. 2014;7:265-268. doi:10.2147/JPR.S65581

2. Mitchell CB. The promise of palliation. Ethics Med Int J Bioeth. 2019;35(2):69-70.

3. Schatman ME, Vasciannie A, Kulich RJ. Opioid moderatism and the imperative of rapprochement in pain medicine. $J$ Pain Res. 2019;12:849-857. doi:10.2147/JPR.S198849

4. Singer JA, Sullum JZ, Schatman ME. Today's nonmedical opioid users are not yesterday's patients: implications of data indicating stable rates of nonmedical and pain reliever use disorder. $J$ Pain Res. 2019;12:617-620. doi:10.2147/JPR.S199750

5. Schatman ME, Wegrzyn EL. The United States Drug Administration and prescription opioid production quotas: an end game of eradication? J Pain Res. 2020;13:2629-2631. doi:10.2147/JPR. S285835

6. Lynch M. The opioid pendulum and the need for better pain care. Pain Med. 2016;17(7):1215-1219. doi:10.1093/pm/pnw085

7. Comerci G Jr, Katzman J, Duhigg D. Controlling the swing of the opioid pendulum. N Engl J Med. 2018;378(8):691-693. doi:10.1056/ NEJMp1713159

8. Rieder TN. There's never just one side to the story: why America must stop swinging the opioid pendulum. Narrat Inq Bioeth. 2018;8 (3):225-231. doi:10.1353/nib.2018.007

9. Brennan MJ, Gudin JA. The prescription opioid conundrum: 21st century solutions to a millennia-long problem. Postgrad Med. 2020;132(1):17-27. doi:10.1080/00325481.2019.1677383

10. Katz B. The science and art of pain management in older persons: case study and discussion. Pain Med. 2012;13(Suppl 2):S72-78. doi:10.1111/j.1526-4637.2011.01315.x
11. Perret D, Chang EY, Pang W, Shinada S, Panush RS. Reflecting on pain management for patients with osteoarthritis and other rheumatic disorders: there's more to pain management than managing pain. Pain Manag. 2013;3(4):295-301. doi:10.2217/pmt.13.30

12. Malhotra N, Joshi M, Gehdoo RP, Usmani H, Sharma G. Pain medicine as a career. Indian $J$ Anaesth. 2021;65(1):73-78. doi:10.4103/ija.IJA_1598_20

13. Gallagher RM; Primary care and pain medicine. A community solution to the public health problem of chronic pain. Med Clin $\mathrm{N} \mathrm{Am}$. 1999;83:555-583. doi:10.1016/S0025-7125(05)70124-3

14. Nijs J, Roussel N, Paul van Wilgen C, Köke A, Smeets R. Thinking beyond muscles and joints: therapists' and patients' attitudes and beliefs regarding chronic musculoskeletal pain are key to applying effective treatment. Man Ther. 2013;18(2):96-102. doi:10.1016/j. math.2012.11.001

15. Bendelow G. Chronic pain patients and the biomedical model of pain. Virtual Mentor. 2013;15(5):455-459. doi:10.1001/virtualmentor.2013.15.5.msoc1-1305

16. Collen M. Operationalizing pain treatment in the biopsychosocial model: take a Daily "SWEM"-socialize, work, exercise, meditate. $J$ Pain Palliat Care Pharmacother. 2015;29(3):290-299. doi:10.3109/15360288.2015.1063563

17. Thorn BE. Ronald Melzack Award Lecture: putting the brain to work in cognitive behavioral therapy for chronic pain. Pain. 2020;161 (Supp11):S27-S35. doi:10.1097/j.pain.0000000000001839

18. Nuernberg Back CG, Liebano RE, Avila Ma. Perspectives of implementing the biopsychosocial model to treat chronic musculoskeletal pain in primary health care. Pain Manag. 2021;11(2):217-225. doi:10.2217/pmt-2020-0024

19. Ickmans K, Moens M, Putman K, et al. Back school or brain school for patients undergoing surgery for lumbar radiculopathy? Protocol for a randomised, controlled trial. J Physiother. 2016;62(3):165. doi:10.1016/j.jphys.2016.05.009

20. King R, Robinson V, Elliott-Button HL, Watson JA, Ryan CG, Martin DJ. Pain Reconceptualisation after pain neurophysiology education in adults with chronic low back pain: a qualitative study. Pain Res Manag. 2018;2018:3745651. doi:10.1155/2018/3745651

21. Smith T. Risks of addiction with prescription opioids underestimated. Richmond Times-Dispatch; October 23, 2015. Available from: https://richmond.com/life/health/risks-of-addiction-with-prescriptionopioids-underestimated/article_705f0bb9-7341-59ad-acd5 -6bf2d100c9cb.html. Accessed October 28, 2021.

22. Testimony of Keith Humphreys to House Judiciary Subcommittee on Immigration and Border Security, February 15, 2018. Hearing on Immigration and the Opioid Crisis. Available from: https://republi cans-judiciary.house.gov/wp-content/uploads/2018/02/WitnessTestimony-Keith-Humphreys.pdf. Accessed October 28, 2021.

23. Ilgen MA, Kleinberg F, Ignacio RV, et al. Noncancer pain conditions and risk of suicide. JAMA Psychiatry. 2013;70:692-697. doi:10.1001/ jamapsychiatry.2013.908

24. Volkow N Suicide deaths are a major component of the opioid crisis that must be addressed. Nora's Blog; September 19, 2019. Available from: https:/www.drugabuse.gov/about-nida/noras-blog/2019/09/sui cide-deaths-are-major-component-opioid-crisis-must-be-addressed. Accessed October 28, 2021.

25. Koesling D, Bozzaro C. Chronic pain patients' need for recognition and their current struggle. Med Health Care Philos. 2021;24 (4):563-572. doi:10.1007/s11019-021-10040-5

26. Schatman ME, Petersen EA, Sayed D. No zero sum in opioids for chronic pain: neurostimulation and the goal of opioid sparing, not opioid eradication. J Pain Res. 2021;14:1809-1812. doi:10.2147/ JPR.S323661

27. Mariano ER, Schatman ME. A commonsense patient-centered approach to multimodal analgesia within surgical enhanced recovery protocols. J Pain Res. 2019;12:3461-3466. doi:10.2147/JPR. S238772 
28. Yennurajalingam S, Arthur J, Reddy S, et al. Frequency of and factors associated with nonmedical opioid use behavior among patients with cancer receiving opioids for cancer pain. JAMA Oncol. 2021;7(3):404-411. doi:10.1001/jamaoncol.2020.6789

29. Jairam V, Yang DX, Verma V, Yu JB, Park HS. National patterns in prescription opioid use and misuse among cancer survivors in the United States. JAMA Netw Open. 2020;3(8):e2013605. doi:10.1001/ jamanetworkopen.2020.13605

30. Schatman ME, Shapiro H, Wegrzyn EL. Questionable conceptualizations of nonmedical use can contribute to needless distress. JAMA Oncol. 2021;7(6):941-942. doi:10.1001/jamaoncol.2021.0569

31. Jantarada C, Silva C, Guimarães-Pereira L. Prevalence of problematic use of opioids in patients with chronic noncancer pain: a systematic review with meta-analysis. Pain Pract. 2021;21 (6):715-729. doi:10.1111/papr.13001

32. Edlund MJ, Martin BC, Fan MY, Devries A, Braden JB, Sullivan MD. Risks for opioid abuse and dependence among recipients of chronic opioid therapy: results from the TROUP study. Drug Alcohol Depend. 2010;112 (1-2):90-98. doi:10.1016/j.drugalcdep.2010.05.017
33. Wilsey BL, Fishman SM, Tsodikov A, Ogden C, Symreng I, Ernst A. Psychological comorbidities predicting prescription opioid abuse among patients in chronic pain presenting to the emergency department. Pain Med. 2008;9:1107-1117. doi:10.1111/j.15264637.2007.00401.x

34. Darnall BD, Juurlink D, Kerns RD, et al. International stakeholder community of pain experts and leaders call for an urgent action on forced opioid tapering. Pain Med. 2019;20:429-433. doi:10.1093/pm/ pny 228

35. Costello KL. Quality of medical advice for chronic pain on social platforms. Proceedings of the 82nd Annual Meeting of the Association for Information Science \& Technology; Melbourne, Australia; October 19-23, 2019. Available from: http://k8lin.com/ pubs/Costello_2019_QualityMedAdvice.pdf. Accessed October 28, 2021.

\section{Publish your work in this journal}

The Journal of Pain Research is an international, peer reviewed, open access, online journal that welcomes laboratory and clinical findings in the fields of pain research and the prevention and management of pain. Original research, reviews, symposium reports, hypothesis formation and commentaries are all considered for publication. The manuscript management system is completely online and includes a very quick and fair peer-review system, which is all easy to use. Visit http:// www.dovepress.com/testimonials.php to read real quotes from published authors. 